\title{
COMPARISON BETWEEN ADDITION OF FENTANYL VERSUS DEXMEDETOMIDINE TO BUPIVACAINE IN ULTRASOUND GUIDED PARAVERTEBRAL NERVE BLOCK AS ANALGESIA IN LAPAROSCOPIC CHOLECYSTECTOMY
}

\author{
By
}

\section{Ahmed Abduljalil Ahmed Marzouq, Mohammed Gamal Mohammed Afifi and Mohamed Ahmed El-Badawy Mohamed}

Department of Anesthesia and Intensive Care, Faculty of Medicine, Al-Azhar University

Corresponding author: Ahmed Abduljalil Ahmed Marzouq,

Mobile: 01101518035, E-mail: taleenahmed991@ gmail.com

\begin{abstract}
Background: Post-operative pain in laparoscopic cholecystectomy is variable, multifactorial and unpredictable. The use of ultrasound-guided paravertebral nerve blocks (PVB) has been explored as part of its multi-modal pain management.

Objective: To evaluate the efficacy of adding fentanyl and dexmedetomidine as adjuvants to bupivacaine in ultrasound guided paravertebral block for patients undergoing laparoscopic cholecystectomy.

Patients and methods: This study was a prospective randomized controlled study that was conducted at AlAzhar University Hospitals. The study included 90 patients who underwent US guided paravertebral block during laparoscopic cholecystectomy. The cases were randomly divided into three equal groups control bupivacaine group, the fentanyl group and the dexmedetomidine group.

Results: visual analogue scale (VAS) during rest was statistically significantly lower in dexmedetomidine group at 1 hour, 2-hours, 6-hours, 12 hours and 24 hours postoperatively as compared with other groups. There were statistically significant differences found between the three groups regarding total dose of morphine. The total dose was statistically significantly lower in the dexmedetomidine group aa compared with the other groups.

Conclusion: The use of a Dexmedetomidine as an adjuvant to bupivacaine was associated with less pain intensity and prolonged duration of analgesia as compared with fentanyl plus bupivacaine or bupivacaine alone, with no change or affection of the incidence of postoperative complications.
\end{abstract}

Keywords: Fentanyl, Dexmedetomidine, Bupivacaine, Ultrasound, Paravertebral Nerve Block, Laparoscopic Cholecystectomy.

\section{INTRODUCTION}

Laparoscopic cholecystectomy is one of the most commonly performed minimally invasive surgical procedures for the treatment of symptomatic cholelithiasis (Harju et al., 2013).
Laparoscopic cholecystectomy has clear benefits when compared with open surgery, but post-operative pain is still a common complaint after it (Evers et al., 2017). 
The patient undergoing laparoscopic cholecystectomy suffers from severe postoperative pain, that pain if not managed appropriately; it can prolong hospital stay and lead to increased morbidity (Chang et al., 2015). Post-operative laparoscopic cholecystectomy pain can be relieved by some methods including various analgesic modalities eg, use of non-steroidal antiinflammatory drugs such as ketorolac (Sharma et al., 2015), pre-emptive analgesic regimens containing ketamine, intraperitoneal local anesthetics, infiltration of the incision site with local anesthetics, and regional anesthesia techniques including paravertebral block (Campiglia et al., 2010).

Paravertebral Block (PVB) is a regional anesthetic and analgesic technique which may offer comparable analgesic effectiveness with minimal side effects. Paravertebral Block has been used a lot in the last two decades; several studies show its efficacy in breast surgery, thoracoscopic surgery and laparoscopic cholecystectomy (Wahba \& Kamal, 2014 and Kulhari et al., 2016). (PVB)is the technique of injecting local anesthetic adjacent to the thoracic vertebra close to where the spinal nerves emerge from the intervertebral foramina, resulting in ipsilateral somatic and sympathetic nerve blockade in multiple dermatomes above and below the site of injection (Gupta et al., 2017).

Bupivacaine is a local anesthetic that is capable of producing prolonged high quality analgesia in the postoperative period (Bani-Hashem et al., 2011). It is shown that paravertebral block using bupivacaine significantly reduces pain score (Golembiewski and Dasta, 2015).
Many drugs have been used as adjuvants to local anesthetic in peripheral nerve block in order to augment its analgesic effect and prolong the duration of the block such as opioids, benzodiazepines, a2 agonists, N-methyl D-aspartate receptor antagonist, dexamethasone, neostigmine and magnesium sulfate (Barreveld et al., 2013).

Dexmedetomidine, when given with opioids, may produce an additive or a synergistic effect (Kim et al., 2013). Dexmedetomidine, an imidazole derivative, is an adrenoceptor agonist with high selectivity for $\alpha 2$ receptors. Dexmedetomidine produces dose-related analgesia sedation, and anxiolysis, without respiratory depression. Postoperative administration produces analgesia without severe sedation (Fahmy et al., 2015).

Although opioids are highly effective in pain control, opioid use can lead to extended hospital stay due to undesirable adverse effects such as respiratory depression, nausea, vomiting, pruritus, and urinary retention (Koepke et al., 2018).

Fentanyl administration is simple and reliable. It improves the quality of intraoperative and early postoperative $\mathrm{s}$ block when added to bupivacaine (Nasef et al., 2019).

The aim of our study was to evaluate the efficacy of adding fentanyl and dexmedetomidine as adjuvants to bupivacaine in ultrasound guided paravertebral block for patients undergoing laparoscopic cholecystectomy regarding the severity of postoperative pain, postoperative opioid consumption in the 1 st 24 hours, incidence of side effects and duration of analgesia. 


\section{PATIENTS AND METHODS}

This was a prospective randomized double-blind study conducted at Al-Azhar University Hospitals, Cairo, Egypt.

The study included 90 patients (underwent ultrasound guided paravertebral block during laparoscopic cholecystectomy) that were randomly allocated (by sealed opaque envelopes technique) into three equal of groups; Control group (patients received $17 \mathrm{~mL}$ of $0.25 \%$ bupivacaine $+3 \mathrm{~mL}$ saline $0.9 \%$ in a total volume of $20 \mathrm{ml}$ on each side), fentanyl group patients received $17 \mathrm{~mL}$ of $0.25 \%$ bupivacaine + fentanyl $(0.25$ $\mu \mathrm{g} / \mathrm{kg}$ ) diluted in $3 \mathrm{ml}$ of $0.9 \%$ saline in a total volume of $20 \mathrm{ml}$ on each side) and dexmedetomidine group (patients received $17 \mathrm{~mL}$ of $0.25 \%$ bupivacaine+ dexmedetomidine $(0.50 \mu \mathrm{g} / \mathrm{kg})$ diluted in $3 \mathrm{ml}$ of $0.9 \%$ saline in a total volume of $20 \mathrm{ml}$ on each side).

\section{Inclusion criteria:}

- American Society of Anesthesiologists physical status grade I and grade II.

- Both sexes will be included.

- age between 20-60 years.

\section{Exclusion criteria:}

- Patient refusal to participate.

- Neuromuscular diseases (as myopathies, myasthenia gravies).

- Hematological diseases, bleeding or coagulation abnormality.

- Psychiatric diseases.

- Local skin infection and sepsis at site of the block.

- Known hypersensitivity to the study drugs.
- Severe chest wall deformity, e.g. scoliosis.

- Morbid obesity.

A written informed consent was obtained from each patient fulfilling inclusion criteria after full explanation of the operation, its benefits and its possible subsequent complications.

All patients were subjected to the following:

1. Full history taking.

2. Clinical examination.

3. Routine preoperative investigations (complete blood picture, coagulation profile, liver function and renal function tests).

\section{Preoperative preparation:}

- All patients were familiar with the use of $0-10$ visual analogue scale score identifying 0 as no pain and 10 as worst imaginable pain.

- On arrival to the operating room routine monitoring was applied, peripheral intravenous cannula (20G) was inserted and $0.9 \%$ saline was started to be infused. All patients were premedicated using midazolam 0.03 $\mathrm{mg} / \mathrm{kg}$ intravenously.

- Paravertebral block was performed before induction of general anesthesia.

Technique of ultrasound guided paravertebral nerve block:

- Standard precautions for the performance of ultrasound- guided nerve blocks were followed which include continuous routine monitoring, the skin overlying the injection site should be free of signs of infection 
and prepped with an antiseptic solution.

- Patient laid in the lateral position, paravertebral block was done using a $38 \mathrm{~mm}$ broadband linear array ultrasound probe. The probe surface in contact with the skin was covered with a sterile adhesive dressing.

- A sagittal paramedian view of the paravertebral space was obtained by applying the probe at a point $2.5 \mathrm{~cm}$ lateral to the tip of the spinous process in a vertical orientation, the fifth thoracic vertebral level was identified by palpating and counting down from the seventh cervical body.

- The midpoint of the transducer was aligned midway between the spine processes of $\mathrm{T} 5$ and $\mathrm{T} 6,4 \mathrm{ml}$ of $1 \%$ lidocaine was injected subcutaneously at the puncture site and $22 \mathrm{G}$ spinal needle was inserted in an in-plane approach in a cephalad orientation and advanced perpendicularly to all skin planes under direct vision to puncture the superior costo-transverse ligament where a click appreciated.

- Following negative aspiration, 1-2 ml of the study, solution was injected to verify correct position of the needle tip and the rest of study solution was injected in fractioned doses following intermittent aspiration between the superior costo- transverse ligament and the parietal pleura which was displaced anteriorly by the injectate.

- Similar approach was used for the paravertebral block on the other side.

- Sensory block over the area of surgical incision was confirmed by loss of cold sensation using an alcohol swab and pinprick sensation using a $23 \mathrm{G}$ needle every $3 \mathrm{~min}$ until $15 \mathrm{~min}$ after injection of the study solutions and before starting general anesthesia.

\section{General Anesthesia:}

- General anesthesia was induced using intravenous propofol $(2-3 \mathrm{mg} / \mathrm{kg})$, fentanyl IV $(1 \mu / \mathrm{kg})$ and atracurium besylate $(0.6 \mathrm{mg} / \mathrm{kg})$ to facilitate intubation then patients were mechanically ventilated using a volume control mode with Tv 6$8 \mathrm{ml} / \mathrm{kg}$, RR $10-14$ breath/min and I.E. ratio $1: 2$ to maintain Etco2 35- 40 $\mathrm{mmHg}$. Anesthesia was maintained using minimum alveolar concentration of isoflurane $1.2 \%$ and $60 \%$ air in $\mathrm{O} 2$ mixture with top up dose of atracurium.

- Intraoperative IV fluids were given according to the body weight and according to intraoperative loss.

- All patients were extubated at the end of surgery after neuromuscular reversal with administration of neostigmine $(0.05 \mathrm{mg} / \mathrm{kg})$ and IV atropine $(0.02 \mathrm{mg} / \mathrm{kg})$ and fulfilling the criteria of extubation. The duration of the surgery was recorded

\section{Intra-operative Assessment:}

- In operating room, monitoring was achieved by five lead ECG, Spo2 and non-invasive MAP, ETCo2 and Temp.

- Base line values of HR, Spo2 and noninvasive MAP will be collected before and after paravertebral block, just after induction of anesthesia, at skin incision, then recording was be done every $15 \mathrm{~min}$ till the end of the first hour and then every 30min interval till the end of surgery. 
- Sensory block onset was defined when the patient subjectively evaluate the intensities of both cold and pinprick sensations in the blocked side decrease $75 \%$ or more.

- Duration of surgery was defined as the time from induction to discharge from the operating room was recorded.

- In case of increased in intra-operative systolic blood pressure and heart rate of more than $20 \%$ of baseline for longer than $5 \mathrm{~min}$, incremental doses of fentanyl IV $0.5 \mu / \mathrm{kg}$ was given and the case was excluded.

\section{Postoperative Assessment:}

- On admission into the PACU, all vital data \& hemodynamics (non- invasive MAP, HR, and SaPO2) were be recorded at 1, 2, 6, 12 and $24 \mathrm{hrs}$. post-operatively.

- Pain intensity was assessed at rest and during coughing with the 10-point VAS score at 1, 2, 6, 12 and 24 hours. post-operatively.

- Visual Analogue Scale consists of a straight line with the endpoints defining extreme limits such as "no pain at all: 0 ' and 'the worst imaginable pain: 10'. The patient's pain level was marked on the line between the two endpoints. The distance between 'no pain at all' and the mark then defines the subject's pain (10).

- When the patients experience pain (VAS score >3), a bolus dose of IV morphine $\quad 0.02 \quad \mathrm{mg} / \mathrm{kg}$ was administered and repeated every 15 min till visual analogue scale score $\leq 4$ was attained.
- The time of first post-operative administration of morphine was recorded.

- The total dose of post-operative morphine $(\mathrm{mg})$ consumed in the first postoperative $24 \mathrm{hrs}$. was calculated in the three groups.

- Post-operative complications were recorded including post- operative nausea and vomiting treated by metoclopramide, hypotension treated by ephedrine, bradycardia treated by atropine or pneumothorax, respiratory depression and chest pain, respiratory depression is defined as respiratory rate less than 8 per minute or $\mathrm{SaPO} 2$ below $90 \%$.

\section{Statistical analysis:}

The collected data were coded, processed and analyzed using the SPSS (Statistical Package for the Social Sciences) version 22 for Windows ${ }^{\circledR}$ (IBM SPSS Inc, Chicago, IL, USA). Data were tested for normal distribution using the Shapiro Wilk test. Qualitative data were represented as frequencies and relative percentages. Chi square test $(\chi 2)$ or Fischer's exact and Bonferroni post-hoc test was be used to calculate difference between groups of qualitative variables. Quantitative data were expressed as mean \pm SD (Standard deviation) or median (interquartile range). The comparison between more than two independent groups with quantitative data was conducted using one-way analysis of the variance (One-way ANOVA) for parametric data and Kruskal -Wallis test for non-parametric data. $\mathrm{P}$ value $<0.05$ was considered significant. 


\section{RESULTS}

The mean age of the cases in the control group was $40.1 \pm 9.86$ years, in the fentanyl group was $41.57 \pm 9.3$ years and in the Dexmedetomidine was $40.8 \pm$ 9.54 years. Male predominate in the three groups represented $60 \%, 63.3 \%$ and $66.7 \%$ in the three groups respectively. There was no statistically significant difference found between the three groups regarding age, sex, weight $(\mathrm{kg})$, Height (m) BMI and ASA classification and duration of surgery (min).

There were statistically significant differences found between the three groups regarding Mean onset of sensory block (min) and Mean duration of sensory block ( $\mathrm{min})$.

The mean onset of sensory block was statistically significantly longer in the control group as compared with other groups. it was significantly longer in the fentanyl group as compared with the Dexmedetomidine group. The mean duration was statistically significantly shorter in the control group as compared with other groups and in the fentanyl group as compared with the Dexmedetomidine group (Table 1).

Table (1): Comparison between Control group ,Fentanyl Group and Dexmedetomidine Group regarding demographic data, operative data and early postoperative outcomes

\begin{tabular}{|c|c|c|c|c|c|}
\hline X & Groups & $\begin{array}{c}\text { Control } \\
\text { group }\end{array}$ & $\begin{array}{c}\text { Fentanyl } \\
\text { Group }\end{array}$ & $\begin{array}{c}\text { Dexmedetomidine } \\
\text { group }\end{array}$ & P-value \\
\hline Variab & & No. $=30$ & No. $=30$ & No. $=30$ & \\
\hline & ge & $40.1 \pm 9.86$ & $41.57 \pm 9.3$ & $40.8 \pm 9.54$ & 0.839 \\
\hline Sox & Males & $18(60.0 \%)$ & $19(63.3 \%)$ & $20(66.7 \%)$ & 0875 \\
\hline Sex & Females & $12(40.0 \%)$ & $11(36.7 \%)$ & $10(33.3 \%)$ & $0.8 / 5$ \\
\hline & ht (kg) & $83.56 \pm 10.76$ & $86.97 \pm 6.75$ & $86.97 \pm 6.13$ & 0.179 \\
\hline & t (m) & $1.66 \pm 0.13$ & $1.63 \pm 0.08$ & $1.66 \pm 0.07$ & 0.354 \\
\hline & MI & $31.84 \pm 4.16$ & $33.01 \pm 4.05$ & $31.89 \pm 3.48$ & 0.445 \\
\hline $\mathbf{A S A}$ & I & $16(53.3 \%)$ & $17(56.7 \%)$ & $15(50.0 \%)$ & 0866 \\
\hline ASA & II & $14(46.7 \%)$ & $13(43.3 \%)$ & $15(50.0 \%)$ & 0.866 \\
\hline $\begin{array}{l}\text { Du } \\
\text { sur }\end{array}$ & $\begin{array}{l}\text { ion of } \\
y(\min )\end{array}$ & $77.97 \pm 11.52$ & $80.52 \pm 10.48$ & $77.02 \pm 10.88$ & 0.317 \\
\hline $\begin{array}{r}\text { Mea } \\
\text { sensor }\end{array}$ & $\begin{array}{l}\text { onset of } \\
\text { lock (min) }\end{array}$ & $5.7 \pm 0.35 \mathrm{~A}$ & $4.89 \pm 0.57 \mathrm{~B}$ & $4.33 \pm 0.18 \mathrm{C}$ & $<0.001$ \\
\hline $\begin{array}{r}\text { Mean } \\
\text { sensor }\end{array}$ & $\begin{array}{l}\text { rration of } \\
\text { lock (min) }\end{array}$ & $152.67 \pm 11.81 \mathrm{~A}$ & $183.13 \pm 8.74 \mathrm{~B}$ & $327.57 \pm 23.8 \mathrm{C}$ & $<0.001$ \\
\hline
\end{tabular}


There was no statistically significant difference found between the three groups regarding $\mathrm{SPO}^{2}$ saturation and mean arterial pressure (MAP) at baseline, during the surgery and at the end of surgery also there was no statistically significant difference found between the three groups regarding heart rate at baseline, but there was statistically significant difference found between the 3 groups regarding heart rate at $15 \mathrm{~min}$, at $30 \mathrm{~min}$, at $45 \mathrm{~min}$, rate at $60 \mathrm{~min}$, and at the End of operation (Table 2).

Table (2): Comparison between Control group, Fentanyl Group and Dexmedetomidine regarding Intra operative (SPO${ }^{2}$ saturation, heart rate and mean arterial pressure)

\begin{tabular}{|c|c|c|c|c|c|}
\hline \multicolumn{2}{|c|}{ Groups } & $\begin{array}{l}\text { Control } \\
\text { group }\end{array}$ & $\begin{array}{c}\text { Fentanyl } \\
\text { Group }\end{array}$ & $\begin{array}{c}\begin{array}{c}\text { Dexmedetomidine } \\
\text { group }\end{array} \\
\end{array}$ & \multirow{2}{*}{ P-value } \\
\hline \multicolumn{2}{|c|}{$\begin{array}{l}\text { Intaoparative } \\
\text { vital data }\end{array}$} & No. $=30$ & No. $=30$ & No. $=30$ & \\
\hline \multicolumn{6}{|c|}{ SPO $^{2}$ saturation (\%) } \\
\hline Baseline & Mean \pm SD & $97.68 \pm 0.51$ & $97.58 \pm 1.12$ & $97.96 \pm 2.00$ & 0.530 \\
\hline $15 \mathrm{~min}$ & Mean \pm SD & $97.57 \pm 0.64$ & $97.41 \pm 1.2$ & $97.26 \pm 2.52$ & 0.764 \\
\hline $30 \mathrm{~min}$ & Mean \pm SD & $97.46 \pm 0.75$ & $97.27 \pm 1.24$ & $97.88 \pm 2.76$ & 0.246 \\
\hline $45 \mathrm{~min}$ & Mean \pm SD & $97.3 \pm 0.9$ & $97.21 \pm 1.26$ & $976.04 \pm 2.56$ & 0.258 \\
\hline $60 \mathrm{~min}$ & Mean \pm SD & $97.27 \pm 0.93$ & $97.16 \pm 1.19$ & $97.20 \pm 1.96$ & 0.275 \\
\hline $\begin{array}{l}\text { At the End } \\
\text { of operation }\end{array}$ & Mean \pm SD & $96.82 \pm 0.95$ & $96.92 \pm 1.24$ & $95.80 \pm 5.09$ & 0.301 \\
\hline \multicolumn{6}{|c|}{ Herat rate (Beat/min) } \\
\hline Baseline & Mean \pm SD & $88.97 \pm 9.7$ & $87.83 \pm 10.2$ & $88.93 \pm 11.69$ & 0.894 \\
\hline $15 \mathrm{~min}$ & Mean \pm SD & $92.57 \pm 10.14$ & $89.27 \pm 12.5$ & $82.9 \pm 8.49$ & 0.002 \\
\hline $30 \mathrm{~min}$ & Mean \pm SD & $91.57 \pm 10.14$ & $88.27 \pm 12.5$ & $81.13 \pm 7.31$ & 0.001 \\
\hline $45 \mathrm{~min}$ & Mean \pm SD & $90.57 \pm 10.14$ & $87.27 \pm 12.5$ & $78.97 \pm 8$ & 0.001 \\
\hline $60 \mathrm{~min}$ & Mean \pm SD & $85.63 \pm 11.85$ & $87.47 \pm 9.55$ & $77.97 \pm 7.62$ & 0.001 \\
\hline $\begin{array}{l}\text { At the End } \\
\text { of operation }\end{array}$ & Mean \pm SD & $83.43 \pm 12.02$ & $86.23 \pm 9.69$ & $78.27 \pm 8.3$ & 0.010 \\
\hline \multicolumn{6}{|c|}{ Mean arterial pressure (mmHg) } \\
\hline Baseline & Mean \pm SD & $95.53 \pm 10.21$ & $94.9 \pm 10.39$ & $93.07 \pm 11.54$ & 0.426 \\
\hline $15 \mathrm{~min}$ & Mean \pm SD & $93.6 \pm 8.06$ & $95.2 \pm 7.88$ & $90.93 \pm 10.83$ & 1.711 \\
\hline $30 \mathrm{~min}$ & Mean \pm SD & $91.83 \pm 9.36$ & $92.43 \pm 9.29$ & $89.93 \pm 10.38$ & 0.545 \\
\hline $45 \mathrm{~min}$ & Mean \pm SD & $86 \pm 12.22$ & $88.53 \pm 12.01$ & $89 \pm 10.51$ & 0.580 \\
\hline $60 \mathrm{~min}$ & Mean \pm SD & $85 \pm 12.26$ & $87.1 \pm 12.85$ & $87.3 \pm 9.94$ & 0.352 \\
\hline $\begin{array}{l}\text { At the End } \\
\text { of operation }\end{array}$ & Mean \pm SD & $92.1 \pm 12.27$ & $95.33 \pm 10.84$ & $96.53 \pm 13.32$ & 1.062 \\
\hline
\end{tabular}


There was no statistically significant difference found between the three groups regarding post-operative $\mathrm{SPO}^{2}$ saturation. There was a statistically significant decrease in HR post-induction in the three groups until 1 hour postoperatively (Table 3).

Table (3): Comparison between Control group, Fentanyl Group and Dexmedetomidine regarding postoperative $\left(\mathrm{SPO}^{2}\right.$ saturation, heart rate and mean arterial pressure)

\begin{tabular}{|c|c|c|c|c|c|}
\hline \multirow{2}{*}{\multicolumn{2}{|c|}{ Groups }} & $\begin{array}{c}\text { Control } \\
\text { group }\end{array}$ & $\begin{array}{l}\text { Fentanyl } \\
\text { Group }\end{array}$ & $\begin{array}{c}\text { Dexmedetomi } \\
\text { dine } \\
\text { group } \\
\end{array}$ & \multirow[t]{2}{*}{ P-value } \\
\hline & & No. $=30$ & No. $=30$ & No. $=30$ & \\
\hline \multicolumn{5}{|c|}{$\mathrm{SPO}^{2}$ saturation } & \\
\hline 1 hour & Mean \pm SD & $97.68 \pm 0.51$ & $97.58 \pm 1.12$ & $98.10 \pm 2.91$ & 0.227 \\
\hline 2 hours & Mean \pm SD & $95.13 \pm 3.86$ & $95.99 \pm 3.42$ & $97.64 \pm 1.80$ & 0.088 \\
\hline 6 hours & Mean \pm SD & $94.70 \pm 4.14$ & $95.76 \pm 3.40$ & $96.23 \pm 4.56$ & 0.071 \\
\hline 12 hours & Mean \pm SD & $97.80 \pm 1.77$ & $97.58 \pm 1.12$ & $97.77 \pm 1.89$ & 0.364 \\
\hline 24 hours & Mean \pm SD & $98.05 \pm 1.90$ & $97.97 \pm 1.24$ & $98.15 \pm 1.94$ & 0.329 \\
\hline \multicolumn{5}{|c|}{ heat rate (Beat/minute) } & \\
\hline 1 hour & Mean \pm SD & $83.87 \pm 8.73$ & $90.33 \pm 10.09$ & $85.33 \pm 9.93$ & 0.098 \\
\hline 2 hours & Mean \pm SD & $84.33 \pm 8.43$ & $86.00 \pm 9.96$ & $86.33 \pm 11.04$ & 0.703 \\
\hline 6 hours & Mean \pm SD & $84.50 \pm 17.02$ & $84.83 \pm 9.44$ & $91.00 \pm 7.85$ & 0.070 \\
\hline 12 hours & Mean \pm SD & $92.57 \pm 10.33$ & $87.83 \pm 10.20$ & $94.10 \pm 10.43$ & 0.055 \\
\hline 24 hours & Mean \pm SD & $95.87 \pm 12.16$ & $91.03 \pm 12.16$ & $97.20 \pm 13.60$ & 0.146 \\
\hline \multicolumn{5}{|c|}{ Mean arterial pressure $(\mathrm{mmHg})$} & \\
\hline 1 hour & Mean \pm SD & $83.87 \pm 8.73$ & $90.33 \pm 10.09$ & $85.33 \pm 9.93$ & 0.098 \\
\hline 2 hours & Mean \pm SD & $84.33 \pm 8.43$ & $86.00 \pm 9.96$ & $86.33 \pm 11.04$ & 0.703 \\
\hline 6 hours & Mean \pm SD & $84.50 \pm 17.02$ & $84.83 \pm 9.44$ & $91.00 \pm 7.85$ & 0.070 \\
\hline 12 hours & Mean \pm SD & $92.57 \pm 10.33$ & $87.83 \pm 10.20$ & $94.10 \pm 10.43$ & 0.055 \\
\hline 24 hours & Mean \pm SD & $95.87 \pm 12.16$ & $91.03 \pm 12.16$ & $97.20 \pm 13.60$ & 0.146 \\
\hline
\end{tabular}

VAS during rest was statistically significantly lower in dexmedetomidine group at 1 hour, 2-hours, 6-hours, 12 hours and 24 hours postoperatively as compared with other groups. Moreover, at 2-hours, 6 hours and 12 hours postoperatively, VAS score was significantly higher in the fentanyl group as compared with the control group (Table 4). 
Table (4): Comparison between Control group Fentanyl Group and Dexmedetomidine regarding VAS score

\begin{tabular}{|c|c|c|c|c|c|c|c|c|}
\hline \multirow{2}{*}{\multicolumn{2}{|c|}{$\overbrace{\text { VAS Scores }}^{\text {Groups }}$}} & \multirow{3}{*}{$\begin{array}{c}\begin{array}{c}\text { Control } \\
\text { group }\end{array} \\
\text { No.= 30 } \\
2(1-2)\end{array}$} & \multirow{3}{*}{$\begin{array}{c}\begin{array}{c}\text { Fentanyl } \\
\text { Group }\end{array} \\
\text { No.= } \mathbf{3 0} \\
2(1-2)\end{array}$} & \multirow{3}{*}{$\begin{array}{c}\begin{array}{c}\text { Dexmedetomidine } \\
\text { group }\end{array} \\
\text { No.= 30 } \\
1(0-2)\end{array}$} & \multirow{3}{*}{\begin{tabular}{|c|} 
P-value \\
0.004 \\
\end{tabular}} & \multirow{3}{*}{$\begin{array}{c}\mathbf{P 1} \\
0.045\end{array}$} & \multirow{3}{*}{$\begin{array}{c}\text { P2 } \\
0.003\end{array}$} & \multirow{3}{*}{$\begin{array}{c}\text { P3 } \\
0.046\end{array}$} \\
\hline & & & & & & & & \\
\hline 1 hour & $\begin{array}{c}\text { Median } \\
\text { (IQR) }\end{array}$ & & & & & & & \\
\hline 2 hours & $\begin{array}{c}\text { Median } \\
\text { (IQR) }\end{array}$ & $5(5-5)$ & $6(6-6)$ & $4(4-4)$ & $<0.001$ & $<0.001$ & $<0.001$ & $<0.001$ \\
\hline 6 hours & $\begin{array}{c}\text { Median } \\
\text { (IQR) }\end{array}$ & $6(5.5-6)$ & $7(6.5-7)$ & $3(2-4)$ & $<0.001$ & $<0.001$ & $<0.001$ & $<0.001$ \\
\hline 12 hours & $\begin{array}{c}\text { Median } \\
\text { (IQR) }\end{array}$ & $4(3-4)$ & $5(4.5-5)$ & $4(3-5)$ & $<0.001$ & $<0.001$ & 0.852 & 0.001 \\
\hline 24 hours & $\begin{array}{c}\text { Median } \\
\text { (IQR) }\end{array}$ & $1(1-2)$ & $1(1-2)$ & $2(1-2.5)$ & 0.010 & 1.000 & 0.039 & 0.039 \\
\hline & & $\begin{array}{l}\text { P1: Sig } \\
\text { Pignifica } \\
\text { Signific }\end{array}$ & $\begin{array}{l}\text { ance be } \\
\text { etween } \\
\text { betwee }\end{array}$ & $\begin{array}{l}\text { control group a } \\
\text { nyl Group and d } \\
\text { rol Group and d }\end{array}$ & $\begin{array}{l}\text { ntanyl } \\
\text { edetom } \\
\text { detom }\end{array}$ & $\begin{array}{l}\text { p } \\
\text { group } \\
\text { group }\end{array}$ & & \\
\hline
\end{tabular}

There was no statistically significant difference found between the three groups regarding complications. There was statistically significant difference found between the three groups regarding Total dose of morphine. The total dose was statistically significantly higher in the control group as compared with other groups, and in the fentanyl group as compared with the Dexmedetomidine group (Table 5).

Table (5): Comparison between Control group,Fentanyl Group and Dexmedetomidine regarding post-operative complications and dose of morphine required

\begin{tabular}{|c|c|c|c|c|c|c|c|}
\hline \multirow{2}{*}{ Complications } & \multicolumn{2}{|c|}{$\begin{array}{c}\text { Control } \\
\text { group }\end{array}$} & \multicolumn{2}{|c|}{$\begin{array}{c}\text { Fentanyl } \\
\text { Group }\end{array}$} & \multicolumn{2}{|c|}{$\begin{array}{l}\text { Dexmedetomidine } \\
\text { group }\end{array}$} & \multirow[t]{2}{*}{ P-value } \\
\hline & No. & $\%$ & No. & $\%$ & No. & $\%$ & \\
\hline \multicolumn{8}{|l|}{ Complications } \\
\hline Nausea & 2 & $6.7 \%$ & 5 & $16.7 \%$ & 4 & $13.3 \%$ & 0.484 \\
\hline Vomiting & 3 & $10.0 \%$ & 4 & $13.3 \%$ & 2 & $6.7 \%$ & 0.690 \\
\hline Brady cardia & 2 & $6.7 \%$ & 4 & $13.3 \%$ & 4 & $13.3 \%$ & 0.638 \\
\hline Shivering & 3 & $10.0 \%$ & 2 & $6.7 \%$ & 0 & $0.0 \%$ & 0.227 \\
\hline Pruritus & 0 & $0.0 \%$ & 2 & $6.7 \%$ & 0 & $0.0 \%$ & 0.129 \\
\hline Hypotension & 1 & $3.3 \%$ & 4 & $13.3 \%$ & 8 & $26.7 \%$ & 0.036 \\
\hline \multicolumn{8}{|c|}{ Total dose of morphine } \\
\hline Mean \pm SD & 6.51 & $2.77 \mathrm{~A}$ & 4.62 & $1.97 \mathrm{~B}$ & 3.0 & $1.83 \mathrm{C}$ & $<0.001$ \\
\hline
\end{tabular}

\section{DISCUSSION}

To the best of our knowledge, this was the first study to evaluate the effect of adding fentanyl and dexmedetomidine as adjuvants to bupivacaine in ultrasound guided paravertebral block for patients undergoing laparoscopic cholecystectomy.

In the current study, there was no statistically significant difference found between the three groups regarding the 
intraoperative and postoperative heart rate and MAP between the three study groups, but there was statistically significant difference found between the three groups regarding heart rate at $15 \mathrm{~min}$, at $30 \mathrm{~min}$, at $45 \mathrm{~min}$, at $60 \mathrm{~min}$, and at the end of operation. The current study showed; a statistically significant decrease in HR post-induction in the three groups until 1 hour postoperatively.

Dexmedetomidine causes stimulation of postsynaptic $\alpha 2$ receptors in the central nervous system, which causes sympathetic inhibition, and so can decrease heart rate and blood pressure Mukherjee et al., (2018) this agreed with Jan et al., (2018). Who showed there no differences in HR and MAP intraoperatively between opioid free anaesthesia( OFA) and opioid-based anesthesia (OA) groups when they measured quality of recovery on Patients undergoing elective laparoscopic bariatric surgery.

On the other hand, it was documented by Gaszyński et al., (2016) when studied patients undergoing bariatric surgery divided into either an opioid free analgesia (OFA) group using dexmedetomidine or a fentanyl-based anesthetic group and significant decrease in HR and MAP in OFA group, Shalaby et al., (2018) found that there were significant decrease in HR and MAP in dexmedetomidine OFA group than fentanyl group after intubation, after pneumoperitoneum, until $60 \mathrm{~min}$ after induction, when studied on 80 patients scheduled for elective laparoscopic cholecystectomy. The difference between the studies could be attributed to different sample size and variations in the dose utilized in these studies.
Pain arises from the incision and trocar sites (50-70\%), and from the rapid distension of peritoneum (20-30\%), with traction on vessels and nerves, irritation of the phrenic nerve, and intra-abdominal trauma (10-20\%), with release of inflammatory mediators. Shoulder pain is usually mild and persists for $24 \mathrm{~h}$ Sarakatsianou et al., (2016).

Naja et al. (2011), compared the effectiveness of bilateral PVB applied preoperatively and postoperatively in patients undergoing laparoscopic cholecystectomy (LC). The PVB was performed under the guidance of a nerve stimulator at thoracic 5 and 6 level either prior to the induction of general anesthesia or immediately after the end of surgery. Patients treated with preoperative PVB were determined to have significantly lower VAS scores for pain at rest, on movement, and on coughing at $12 \mathrm{~h}$ postoperatively. Aydin and Aydin, (2018) showed that The VAS scores for each evaluation were significantly lower in the preoperative and postoperative block groups compared to the control group.

In the current study, VAS during rest was statistically significantly lower in dexmedetomidine group at 1 hour, 2hours, 6-hours, 12 hours and 24 hours postoperatively as compared with other groups. Moreover, at 2-hours, 6 hours and 12 hours postoperatively, VAS score was significantly higher in the fentanyl group as compared with the control group. This result was in accordance with a study conducted by Kumar et al.,( 2014) who compared premedication with the same dexmedetomidine and clonidine in laparoscopic cholecystectomy and found that VAS score was significantly less in 
dexmedetomidine group, Also, our results agreed with Morsy et al., (2017) who compared bupivacaine $0.25 \%$, bupivacaine $0.25 \%$ with dexmedetomidine $100 \mu \mathrm{g}$ and bupivacaine $0.25 \%$ with morphine $2 \mathrm{mg}$ in PVB performed using landmark-guided technique. The authors found that dexmedetomidine group had lower pain scores compared to the other two groups.

Kataria et al.(2016) showed a significant decrease in VAS score in the OFA group when studied on the efficacy of dexmedetomidine versus fentanyl on the pressor response and pneumoperitoneum in laparoscopic cholecystectomy, Shalaby et al., (2018) documented that there was a significant decrease in OFA group regarding VAS scores at 20, 60 minutes and 6 hours postoperatively than the fentanyl group.

A study by Toleska and Dimitrovski (2019) showed that the OFA group statistically significant decrease VAS score at first hour and 24 hours after the surgery than the Fentanyl group, also low VAS score in OFA group with the nonsignificant difference between two groups at other time postoperative, Within the same context, Bhatia et al. (2015) showed that the intrathecal bupivacainedexmedetomidine combination caused significant reduction of the incidence of shoulder tip pain compared with those who received intrathecal bupivacaine alone for laparoscopy. Within the same context, Abdelmoniem et al. (2020) and his colleagues reported that there was a statistically significant decrease in VAS at 0h, 2hs, 4hs, 8hs, 12hs and $24 \mathrm{hrs}$. postoperative in the dexmedetomidine group.
In the current study, there were statistically significant differences found between the three groups regarding mean onset of sensory block (min) and mean duration of sensory block (min). The mean onset of sensory block was statistically significantly longer in the control group as compared with other groups. in the fentanyl group as compared with the Dexmedetomidine groups, and The mean duration of sensory block was statistically significantly shorter in the control group as compared with other groups. The mean duration of sensory block was significantly shorter in the fentanyl group as compared with the Dexmedetomidine group.

Naja et al. (2011) showed that analgesia consumption was also lower in the preoperative PVB group In the study conducted by Aydin and Aydin (2018), after the preoperative application of unilateral paravertebral block, none of patients required any opioids during surgery. Furthermore, patients in both the preoperative and postoperative groups requested significantly less analgesia compared to the control group.

Therefore, as even unilateral PVB can induce this analgesic effect, it can be considered that pneumoperitoneum, which is expected to induce diffuse pain bilaterally, does not significantly contribute to the pain during and after LC, Our results agreed with Morsy et al. (2017) who compared bupivacaine $0.25 \%$, bupivacaine $0.25 \%$ with dexmedetomidine $100 \mu \mathrm{g}$ and bupivacaine $0.25 \%$ with morphine $2 \mathrm{mg}$ in PVB performed using landmark-guided technique. They found that dexmedetomidine group had prolonged analgesia, reduced post- 
operative pethidine consumption and more sedated patients compared to the other two groups.

In another study, dexmedetomidine 1 $\mu \mathrm{g} / \mathrm{kg}$ added to $0.25 \%$ bupivacaine in PVB was shown to significantly prolong the mean time to first rescue analgesic as compared to $0.25 \%$ bupivacaine alone Mohamed et al. (2014). Mohta et al., (2016) reported that paravertebral block using $1 \mu \mathrm{g} / \mathrm{kg}$ dexmedetomidine combined with $0.5 \%$ bupivacaine provided longer duration of anesthesia with decreased post-operative opioid consumption and lower incidence of nausea and vomiting compared with bupivacaine alone .Moreover, Hetta et al. (2018) reported that epidural infusion of dexmedetomidine combined with bupivacaine reduced morphine consumption delayed the time to first analgesic supplementation and decreased pain intensity in patients undergoing major abdominal cancer surgery and epidural blocks.

Ganesh and Krishnamurthy (2018) reported that dexmedetomidine combined with bupivacaine administered intrathecally exhibited a faster onset of motor and sensory block and prolonged the duration of anesthesia in patients undergoing spinal block (Mangal et al., 2018). Demonstrated that the addition 1 $\mu \mathrm{g} / \mathrm{kg}$ dexmedetomidine to $0.75 \%$ ropivacaine in supraclavicular brachial plexus block prolonged the duration of sensory and motor block.

Aksu et al. (2018) demonstrated that addition of dexmedetomidine to bupivacaine in TAP block decreased postoperative pain scores and morphine consumption, and increased patient satisfaction in patients undergoing lower abdominal surgery.

There was a statistically significant difference found between 3 groups regarding total dose of morphine. The total dose was statistically significantly higher in the control group as compared with other groups. in the fentanyl group as compared with the Dexmedetomidine group. This came in accordance with Abdelmoniem et al., (2020) who showed that there was a statistically significant decrease in pethidine consumption in $24 \mathrm{~h}$ postoperative in group II (OFA with Dexmedetomidine) compared to group I (OA).

Samuels et al. (2017) found in a retrospective analysis that the OFA group needed $50 \%$ fewer opioids in postoperative although non-opioid anesthesia did not make any difference. This observation suggests that even exposure to small amounts of opioids intraoperative increases the need for opioids in the postoperative period. (Toleska and Dimitrovski, 2019) found that the opioids needed in the postoperative period were significantly lesser in the OFA group at rest and coughing, compared to the opioid group On the other hand, Ziemann-Gimmel et al.(2014) found no difference in opioid consumption post-operative for the same VAS scores but did not explain what the post-operative period was compared.

In the current study, there was no statistically significant difference between the three groups about postoperative nausea and vomiting (PONV). PONV are also common clinical postoperative symptoms following LC. Incidences of PONV within 24 hours after LC have 
been reported to occur in $53-72 \%$ (De Oliveira Jr et al., 2013).

PONV are distressful experiences for patients that may not only delay discharge from hospital but also lead to dehydration, electrolyte imbalance, suture dehiscence and oesophageal rupture (Hambridge, 2013). Ziemann-Gimmel et al. (2014) found a significant reduction in PONV in the OFA group even when triple PONV prophylaxis was given to both groups Abdelmoniem et al. (2020) who showed that there was a statistically significant decrease in number of patients who developed nausea and vomiting in group II (OFA with Dexmedetomidine), while no statistically significant difference between both groups by bradycardia. On the other hand, the study done by Mansour et al (2013) showed that for obese patients undergoing laparoscopic sleeve gastrectomy, found that there were no statistically significant changes among the OFA\& OA groups as regard to postoperative complications in PACU.

In the current study, there was no statistically significant difference between the two groups as regard to brady cardia, shivering, pururitis and hypotension, We did not encounter respiratory depression, urinary retention, bradycardia and hypotension in any of the patients. This could be attributed to the use of nerve stimulator-guided technique. Improved safety by the nerve stimulator-guided technique has been suggested in previous studies as well (Naja et al., 2013).

The current study had certain limitations. First, the present randomized controlled double-blinded trial was conducted at a single center. Further clinical trials are required at multiple centers in order to generalize the results. Second, whether the action of dexmedetomidine was related to systemic absorption or pure local effect was not fully elucidated.

\section{CONCLUSION}

The use of a Dexmedetomidine as an adjuvant to bupivacaine was associated with less pain intensity and prolonged duration of analgesia as compared with fentanyl plus bupivacaine or bupivacaine alone with no change or affection of the incidence of postoperative complications.

Conflict of interest: Authors declared no conflict of interest.

\section{REFERENCES}

1. Abdelmoniem, M., Farran, H. A., SOLIMAN, S. and Alfy, M. O. (2020): Opioid free anesthesia in patients undergoing three-port laparoscopic cholecystectomy. Al-Azhar International Medical Journal, 1(1): 160-165.

2. Aksu, R., Patmano, G., Biçer, C., Emek, E. and Çoruh, A. E. (2018): Efficiency of bupivacaine and association with dexmedetomidine in transversus abdominis plane block ultrasound guided in postoperative pain of abdominal surgery. Revista Brasileira de Anestesiologia, 68(1): 49-56.

3. Aydin, G. and Aydin, O. (2018): The efficacy of ultrasound-guided paravertebral block in laparoscopic cholecystectomy. Medicina, 54(5): 75-79.

4. Bani-Hashem, N., Hassan-Nasab, B., Pour, E. A., Maleh, P. A., Nabavi, A. and Jabbari, A. (2011): Addition of intrathecal Dexamethasone to Bupivacaine for spinal anesthesia in orthopedic surgery. Saudi Journal of Anaesthesia, 5(4): 382-6. 
5. Barreveld, A., Witte, J., Chahal, H., Durieux, M. E. and Strichartz, G. (2013): Preventive analgesia by local anesthetics: the reduction of postoperative pain by peripheral nerve blocks and intravenous drugs. Anesthesia and Analgesia, 116(5): 1141-61.

6. Bhatia, T., Bhatia, J., Attri, J. P., Singh, S. and Khetarpal, R. (2015): Intrathecal dextmedetomidine to reduce shoulder tip pain in laparoscopic cholecystectomies under spinal anesthesia. Anesthesia, Essays and Researches, 9(3),:320-325.

7. Campiglia, L., Consales, G. and De Gaudio, A. R. (2010): Pre-emptive analgesia for postoperative pain control. Clinical drug investigation, 30(2): 15-26.

8. Chang, S. K. Y., Wang, Y. L., Shen, L., Iyer, S. G. and Madhavan, K. (2015): A randomized controlled trial comparing post-operative pain in single-incision laparoscopic cholecystectomy versus conventional laparoscopic cholecystectomy. World journal of Surgery, 39(4),:897-904.

9. De Oliveira Jr, G. S., Castro-Alves, L. J. S., Ahmad, S., Kendall, M. C. and McCarthy, R. J. (2013): Dexamethasone to prevent postoperative nausea and vomiting: an updated meta-analysis of randomized controlled trials. Anesthesia \& Analgesia, 116(1):58-74.

10. Evers, L., Bouvy, N., Branje, D. and Peeters, A. (2017): Single-incision laparoscopic cholecystectomy versus conventional four-port laparoscopic cholecystectomy: a systematic review and meta-analysis. Surgical endoscopy, 31(9), 3437-344.

11. Fahmy, A., Aboulghate, M., Amin, S. and Abd EL-Hakim, A. (2015): A randomized control study to compare intrathecal dexmedetomidine used as adjuvant to intrathecal Bupivacaine alone in Orthopaedic Surgeries. Med. J. Cairo University,83. 85-89:

12. Ganesh, M. and Krishnamurthy, D. (2018): A comparative study of dexmedetomidine and clonidine as an adjuvant to intrathecal bupivacaine in lower abdominal surgeries. Anesthesia, Essays and Researches, 12(2):539-545.

13. Gaszyński, T., Czarnik, K., Laziński, L. and Gaszyński, W. (2016): Dexmedetomidine for attenuating haemodynamic response to intubation stimuli in morbidly obese patients anaesthetised using low-opioid technique: comparison with fentanyl-based general anaesthesia. Anaesthesiology Intensive Therapy, 48(5): 275-279.

14. Golembiewski, J. and Dasta, J. (2015): Evolving role of local anesthetics in managing postsurgical analgesia. Clinical therapeutics, 37(6): 1354-1371.

15. Gupta, K., Srikanth, K., Girdhar, K. K. and Chan, V. (2017): Analgesic efficacy of ultrasound-guided paravertebral block versus serratus plane block for modified radical mastectomy: A randomised, controlled trial. Indian Journal of Anaesthesia, 61(5): 381-386.

16. Hambridge, K. (2013): Assessing the risk of post-operative nausea and vomiting. Nursing Standard, 27(18): 3543.

17. Harju, J., Aspinen, S., Juvonen, P., Kokki, H. and Eskelinen, M. (2013): Ten-year outcome after minilaparotomy versus laparoscopic cholecystectomy: a prospective randomised trial. Surgical Endoscopy, 27(7): 2512-2516.

18. Hetta, D. F., Fares, K. M., Abedalmohsen, A. M. and Ali, W. N. (2018): Epidural dexmedetomidine infusion for perioperative analgesia in patients undergoing abdominal cancer 
surgery: randomized trial. Journal of Pain Research, 11: 267-2685.

19. Jan, M. , Ruben, W. , Bruno, D. and Marc, D. (2018): A Randomized Controlled, Double-Blind Trial Evaluating the Effect of Opioid-Free Versus Opioid General Anesthesia on Postoperative Pain and Discomfort Measured by the QoR-40. Journal of Clinical Anesthesia and Pain Medicine, 2(1): 1-6.

20. Kataria, A. P., Attri, J. P., Kashyap, R. and Mahajan, L. (2016): Efficacy of dexmedetomidine and fentanyl on pressor response and pneumoperitoneum in laparoscopic cholecystectomy. Anesthesia, Essays and Researches, 10(3):446. -50

21. Kim, J. E., Kim, N. Y., Lee, H. S. and Kil, H. K. (2013): Effects of intrathecal dexmedetomidine on low-dose bupivacaine spinal anesthesia in elderly patients undergoing transurethral prostatectomy. Biological and Pharmaceutical Bulletin, 36(6): 959-965.

22. Koepke, E. J., Manning, E. L., Miller, T. E.. and Manning, M. W. (2018):. The rising tide of opioid use and abuse: the role of the anesthesiologist. Perioperative Medicine, 7(1) 16. :2-8

23. Kulhari, S., Bharti, N., Bala, I., Arora, S. and Singh, G. (2016): Efficacy of pectoral nerve block versus thoracic paravertebral block for postoperative analgesia after radical mastectomy: a randomized controlled trial. BJA: British Journal of Anaesthesia, 117(3): 382-386.

24. Kumar, S., Kushwaha, B., Prakash, R., Jafa, S., Malik, A., Wahal, R. and Verghese M. (2014): Comparative study of effects of dexmedetomidine and clonidine premedication in perioperative hemodynamic stability and postoperative analgesia in laparoscopic cholecystectomy. Internet J Anesthesiolgy, 33 (1):.190-186

25. Mangal, V., Mistry, T., Sharma, G., Kazim, M., Ahuja, N. and Kulshrestha, A. (2018): Effects of dexmedetomidine as an adjuvant to ropivacaine in ultrasoundguided supraclavicular brachial plexus Block: A prospective, randomized, double-blind study. Journal of Anaesthesiology, Clinical Pharmacology, 34(3), 357-361.

26. Mansour, M. A., Mahmoud, A. A. A. and Geddawy, M. (2013): Nonopioid versus opioid based general anesthesia technique for bariatric surgery: A randomized double-blind study. Saudi Journal of Anaesthesia, 7(4): 387-391.

27. Mohamed, S. A., Fares, K. M., Mohamed, A. A. and Alieldin, N. H. (2014): Dexmedetomidine as an adjunctive analgesic with bupivacaine in paravertebral analgesia for breast cancer surgery. Pain Physician, 17(5): 589-598.

28. Mohta, M., Kalra, B., Sethi, A. K. and Kaur, N. (2016): Efficacy of dexmedetomidine as an adjuvant in paravertebral block in breast cancer surgery. Journal of Anesthesia, 30(2): 252-260.

29. Morsy, A. R., Abd-elmaksoud, M. M., Aziz, R. A. A. and Metwally, M. (2017): Comparison between dexmedetomidine versus morphine added to bupivacaine in paravertebral block in patients scheduled for modified radical mastectomy. Research and Opinion in Anesthesia and Intensive Care, 4(2): 59.-64.

30. Mukherjee, A., Das, A., Mayur, N., Bhattacharyya, C., Biswas, H., Mitra, T., Roybasunia $S$ and Mandal SK (2018): Comparative evaluation of analgesic sparing efficacy between dexmedetomidine and clonidine used as adjuvant to ropivacaine in thoracic paravertebral block for patients 
undergoing breast cancer surgery: A prospective, randomized, double-blind study. Saudi Journal of Anaesthesia, 12(4): 548-54.

31. Naja, M., Ziade, M. and Lönnqvist, $P$. (2013): Nerve-stimulator guided paravertebral blockade vs. general anaesthesia for breast surgery: a prospective randomized trial. European Journal of Anaesthesiology, 20(11): 897903.

32. Naja, Z. M., El-Rajab, M., Ziade, F., Al-Tannir, M. and Itani, T. (2011): Preoperative vs. postoperative bilateral paravertebral blocks for laparoscopic cholecystectomy: a prospective randomized clinical trial. Pain Practice, 11(6): 509-515.

33. Nasef, A. E., Abo-Elnasr, L. M., ElSheikh, N. A. and Mohamed, A. E. (2019): Prospective randomized study comparing transversus abdominus plane block and spinal fentanyl added to bupivacaine for postoperative analgesia after cesarean section. Tanta Medical Journal, 47(2):74-79.

34. Samuels, D., Abou-Samra, A., Dalvi, P., Mangar, D. and Camporesi, E. M. (2017): Opioid-free anesthesia results in reduced postoperative opioid consumption. J Clin Anesth Pain Med. 4 (1):205-221.

35. Sarakatsianou, C., Georgopoulou, S. and Tzovaras, G. (2016): Acute pain management in laparoscopic cholecystectomy: Is there a role for pregabalin. A review. The Greek EJournal of Perioperative Medicine, 14: 1524.

36. Shalaby, M., Abdalla, M. and Mahmoud, A. S. (2018): Nonopioid versus opioid based general anesthesia technique for laparoscopic cholecystectomy. The Egyptian Journal of Hospital Medicine, 73(3): 6206-6212.

37. Sharma, M., Kharbuja, K. and Sharma, N. R. (2015): Intraperitoneal hydrocortisone plus bupivacaine versus bupivacaine alone for pain relief after laparoscopic cholecystectomy: A randomized controlled trial. Journal of Lumbini Medical College, 3(2): 41-44.

38. Toleska, M. and Dimitrovski, A. (2019):. Is Opioid-Free General Anesthesia More Superior for Postoperative Pain Versus Opioid General Anesthesia in Laparoscopic Cholecystectomy, Journal of Clinical Anesthesia and Pain Medicine. 40(2): 8187.

39. Wahba, S. S. and Kamal, S. M. (2014): Thoracic paravertebral block versus pectoral nerve block for analgesia after breast surgery. Egyptian Journal of Anaesthesia, 30(2): 129-135.

40. Ziemann-Gimmel, P., Goldfarb, A., Koppman, J. and Marema, R. (2014): Opioid-free total intravenous anaesthesia reduces postoperative nausea and vomiting in bariatric surgery beyond triple prophylaxis. British Journal of Anaesthesia, 112(5): 906-911. 


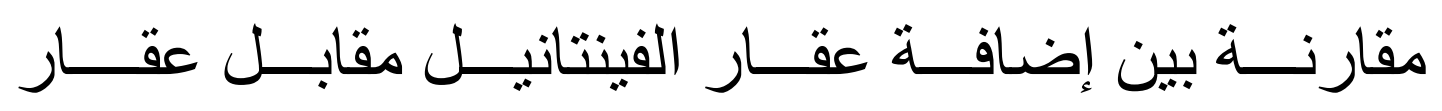

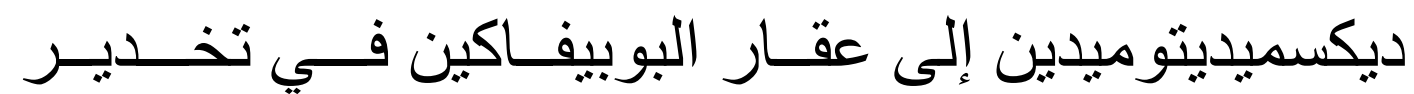

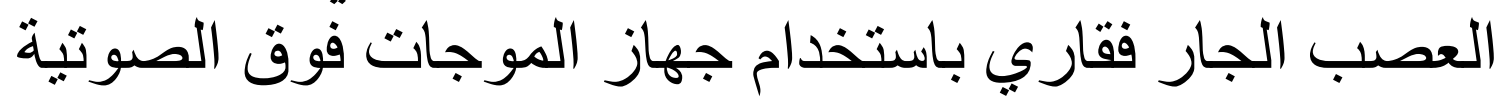

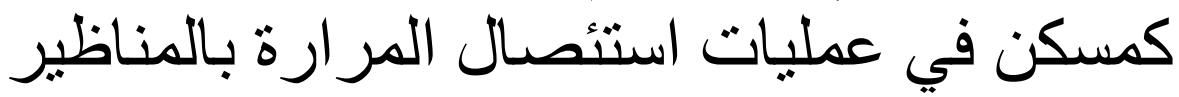

أحمد عبدالجليل أحمد مرزوق، محمد جمال محمد عفيفي، محمد احمد البدوي محمد قسم التخدير والعناية المركزة، كلية الطب، جامعة الأزهر

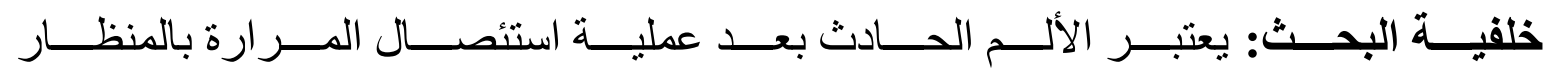

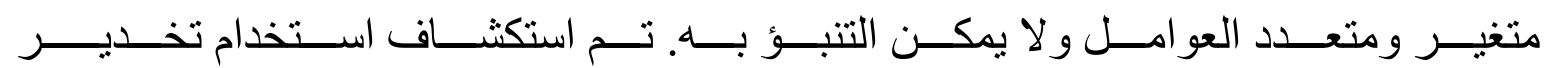

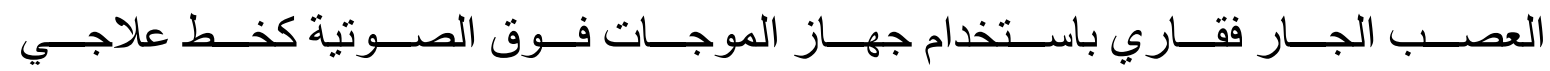
من الوسائل المستخدمة لعلاج الألم عقب تلك العملية.

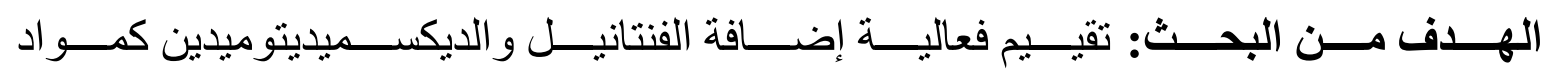

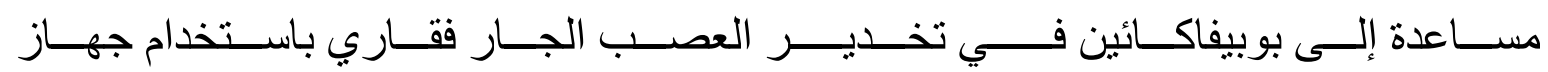
الموجات فوق الصوتية كمسكن في عمليات استئصال المر ارة بالمناظير.

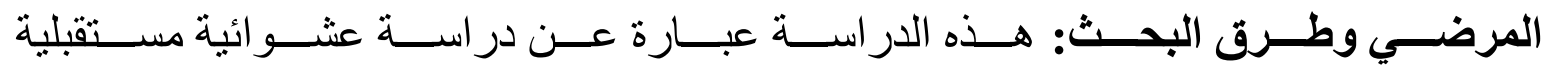

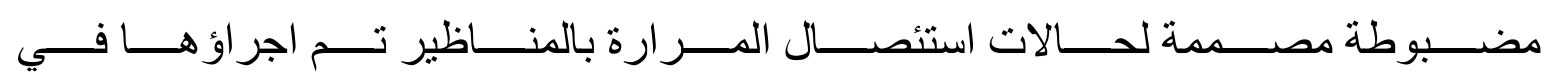

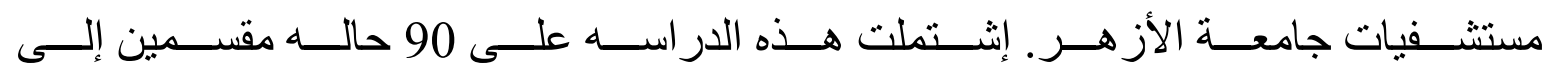

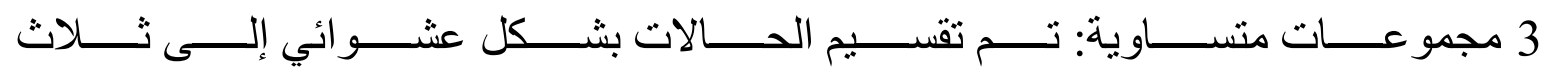

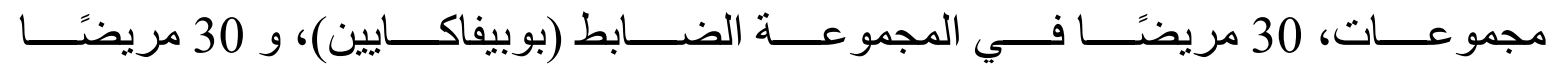
في مجمو عة الفنتانيل و 30 مريضًا في مجمو عة ديكسميدينوميدين.

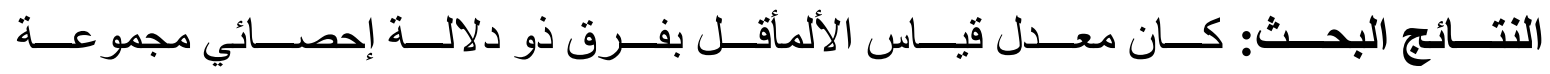

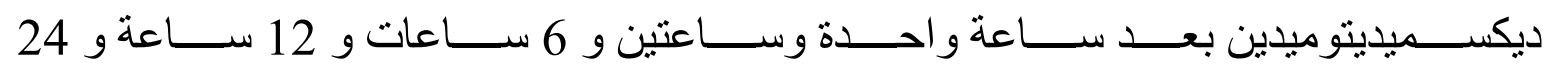

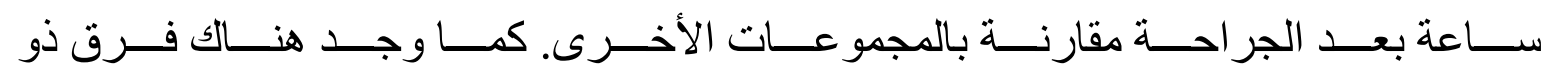

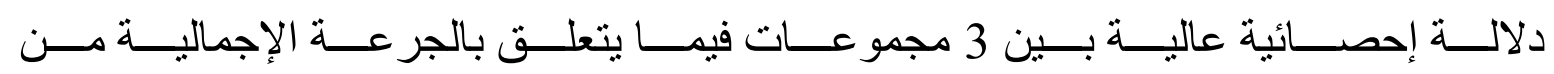




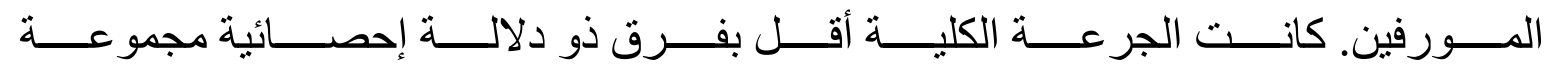
ديكسميديتو ميدين مقارنة مع المجمو عات الأخرى.

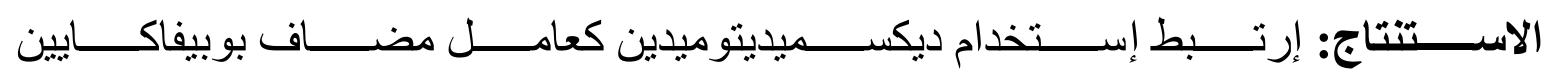

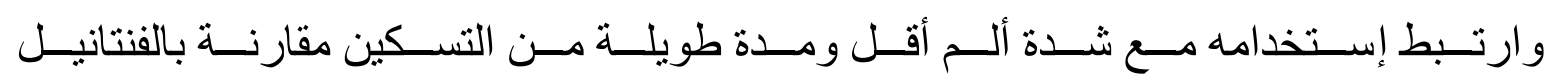

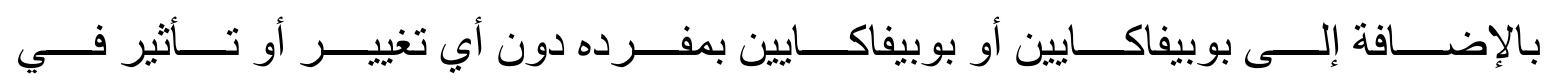
حدوث مضاعفات ما بعد الجر احة.

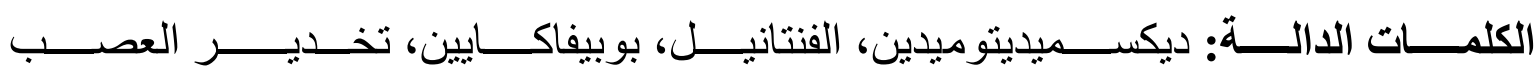
الجار فقاري،الموجات فوق الصوتية، استنصسال المرارة بالمناظير. 